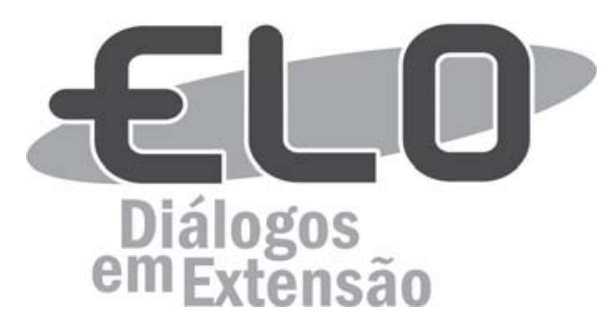

\title{
A percepção da extensão rural no âmbito da graduação nas ciências sociais e agrárias na UFLA
}

Jucilaine Neves Sousa Wivaldo ${ }^{1}$, Suelen Ferreira Matoso Couto ${ }^{2}$, Viviane Santos Pereira ${ }^{3}$,

Daniel Rodrigues Rezende ${ }^{4}$ Fernanda Carvalho ${ }^{5}$ e Maria Dalva Pereira ${ }^{6}$

Resumo: O objetivo do estudo é problematizar a Extensão com os estudantes da disciplina de Fundamentos de Extensão da graduação da Universidade Federal de Lavras (UFLA). A metodologia utilizada foi o mapeamento participativo sendo um diagnóstico de grupo, que teve como finalidade levantar informação do dominio de temas específicos, considerando o contexto social e econômico de cada um dos participantes para assim ser possível dialogar e alinhar o conhecimento desses temas com o grupo todo. Discutiu-se o conhecimento sobre extensão na formação acadêmica fazendo um resgate do conhecimento histórico da extensão rural no Brasil a fim de motivá-los a uma atuação na extensão rural participativa e democrática. Observou-se o distanciamento das instituições de ensino e pesquisa para com a sociedade, sendo que extensão deve ser realizada lugares diversos, pois todos os campos de conhecimento têm abertura para extensão.

Palavras-chave: Extensão. Participação. Estratégias Metodológicas. Mapeamento Participativo.

Área Temática: Extensão.

\section{The perception of rural extension in the scope of graduation in social and agrarian sciences at UFLA}

Abstract: The objective of the study is to problematize the Extension with the students of the subject of Extension Fundamentals of the Universidade Federal de Lavras (UFLA). The methodology used was the participatory mapping as a group diagnosis, which purpose was to gather information from the domain of specific themes, considering the social and economic context of each one of the participants, in order to be able to dialogue and align the knowledge of these themes with the whole group. Knowledge about extension in the academic background was discussed, making a historical knowledge rescue of the rural extension in Brazil in order to motivate them to an action in the rural extension participatory and democratic. It was observed the distance of the teaching and research institutions with the society, and the extension must be made in several places, since all fields of knowledge have openness for extension.

Keywords: Extension. Participation. Methodological Strategies. Participatory Mapping.

\section{La percepción de la extensión rural en el ámbito de la graduación en las ciencias sociales y agrarias en la UFLA}

Resumen: El objetivo del estudio es problematizar la Extensión con los estudiantes de la asignatura de Fundamentos de Extensión de la graduación de la Universidad Federal de Lavras (UFLA). La metodología utilizada fue la cartografía participativo siendo un diagnóstico de grupo, que tuvo como propósito levantar

\footnotetext{
${ }^{1}$ Assistente Social, Mestre em Mestrado profissional Desenvolvimento Sustentável e Extensão, Universidade Federal de Lavras. E-mail:jucilainen@gmail.com; tel: (32) 9 8408-4455.

2 Veterinária, Mestre em Mestrado profissional Desenvolvimento Sustentável e Extensão, Universidade Federal de Lavras,suelenmattoso@hotmail.com

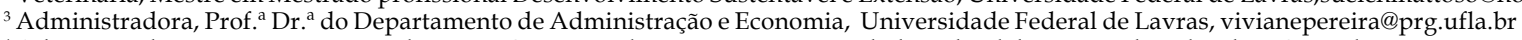

${ }^{4}$ Administrador, Mestre em Desenvolvimento Sustentável e Extensão, Universidade Federal de Lavras, daniel.rod.rez@gmail.com

${ }^{5}$ Engenheira Florestal, Doutora em Engenharia Florestal, Universidade Federal de Lavras, fernandacarva@hotmail.com

${ }^{6}$ Pedagoga, Mestre em Mestrado profissional Desenvolvimento Sustentável e Extensão, Universidade Federal de Lavras, dalvapereira@emater.mg.gov.br
} 
información del dominio de temas específicos, considerando el contexto social y económico de cada uno de los participantes, para así ser posible dialogar y alinear el conocimiento de estos temas con el objeto todo el grupo. Se discutió el conocimiento sobre extensión en la formación académica haciendo un rescate del conocimiento histórico de la extensión rural en Brasil a fin de motivarlos a una actuación en la extensión rural participativa y democrática. Se observó el distanciamiento de las instituciones de enseñanza e investigación con la sociedad, siendo que la extensión debe realizarse lugares diversos, pues todos los campos de conocimiento tienen apertura para extensión.

Palabras clave: Extensión. Participación. Estrategias Metodológicas. Mapeo Participativo.

\section{Introduçao}

No período de 1964 a 1980, a extensão serviu de instrumento do "difusionismo produtivista", a fim de incentivar nos produtores rurais a aquisição do pacote tecnológico modernizante, com uso intensivo de capital (máquinas e insumos industrializados) para aumentar a produtividade e a mudança da mentalidade dos produtores, do "tradicional" para o "moderno".

Entretanto, o esgotamento do "milagre" brasileiro e a instalação da crise econômica, fez com que o serviço de extensão entrasse em crise. Além disso, a extensão foi marcada por críticas como no livro de Paulo Freire "Comunicação ou Extensão?", escrito no Chile em 1969 e publicado no Brasil em 1977, no qual aborda a ideia de que a extensão pretendia substituir uma forma de conhecimento por outra, tendo como objetivo depositar conhecimento de forma vertical e "antidialógica" (MOTA et al., 2006).

Assim, as ações extensionistas que permitiriam os extensionistas refletirem, promovendo embates entre os que estão arraigados nas suas convicções difusionistas e aqueles que têm a percepção da necessidade de mudanças para promoção da prática mais democrática de extensão. Para tanto, o papel dos extensionistas é voltado a "ajudar na construção das condições de autorreflexão que permitirá a retomada da consciência de si e a construção coletiva" (MOTA, 2006, p. 3).

Nesse contexto, "o uso de metodologias participativas, valorizando potencialidades locais e resgatando a autoestima das pessoas, pode ser importante ferramenta para construção de capital social e empoderamento de pessoas historicamente excluídas das decisões políticas" (VIONE, 2002, p. 5). Desse modo, o mapeamento participativo é uma metodologia para compreender e levantar dados, de acordo com a percepção dos indivíduos quanto ao local em que se vive e o contexto de sua realidade, para analisar, por exemplo, conflitos em unidades de conservação e em unidades quilombolas, sendo ainda muito utilizado pela educação ambiental com crianças, jovens, entre outras. Nesse sentido,

À produção de mapa aberto à participação cidadã, na qual se põe em prática um saber cartográfico fundamentado em vivências, memórias, tradição oral, especificidades socioculturais, afetividade, ou seja, todos os elementos que possam contribuir para a construção da identidade de uma comunidade dá-se o nome de Mapeamento Participativo (GOMES, 2015, p. 17).

O objetivo do estudo foi problematizar a extensão rural no Brasil com estudantes da disciplina de Fundamentos de Extensão, formada pelos cursos de Direito, Agronomia, Engenharia Ambiental e Sanitária, Administração, Engenharia Florestal, Zootecnia, Química, Letras e Administração, embasados nos trabalhos de Freire (1993), Coelho (2014), Acselrad, H. (2008), Colchester (2002) e Tuan (2012), Capra (2002); de maneira a compreender o conhecimento e a percepção da realidade dos graduandos, da disciplina de Extensão e do estímulo a reflexão a respeito de como a extensão rural era realizada no Brasil no passado, é no presente e será no futuro.

Buscou-se compreender a percepção dos estudantes quanto à importância da construção conjunta de metodologias de extensão e como a formação de cada um pode influenciar positivamente ou negativamente na realidade. Torna-se fundamental que exista a sensibilização e abertura de todos os participantes, objetivando ter um novo olhar perante o que é proposto pelo outro.

Assim, questiona-se: como os estudantes entendem a extensão em sua realidade? Como compreendem seu papel nesse processo de transformação em conjunto, com junção de saberes para construção de um terceiro saber? 
Espera-se com este trabalho promover a socialização de conhecimentos sobre o tema "Extensão Rural"; propiciar a aprendizagem da aplicação de uma técnica participativa; levantar a questão da necessidade de maior conhecimento sobre extensão na formação acadêmica; possibilitar o conhecimento do histórico da extensão rural no Brasil e motivar os estudantes a atuarem nas atividades de extensão rural de forma participativa e democrática.

\title{
Mapeamento participativo e extensão
}

O mapeamento participativo é utilizado para diagnósticos de locais em que os indivíduos vivem pois possibilita que se identifiquem os conflitos ambientais em suas diferentes interfaces e, nesse contexto de estudo, proporcionam aos estudantes a noção de um modo de participarem do mapeamento.

Vale ressaltar que a metodologia "mapeamento participativo" permite adaptar à realidade dos indivíduos e, para isso é fundamental que se conheça primeiramente o grupo no qual será aplicada a metodologia, e, nesse primeiro contato, conhecer suas reais necessidades. Dessa forma, por meio da participação dos pesquisadores com os estudantes durante a ministração da disciplina foi percebido que os mesmos têm urgência em práticas de extensão, para vivenciarem como a mesma se desenvolve na realidade. Percebeu-se durante discussão em aula, a necessidade da participação nas atividades extensionistas.

Acselrad e Coli (2008, p. 38) afirmam que esse mapeamento é forma de "[...] ligar os atores e o território, construir o território com os atores e mobilizar estes atores através do território sob a hipótese de que nessa relação uns e outros se transformam".

Paulo Freire foi um grande influenciador brasileiro para a transformação da extensão no país, de um difusionismo produtivista, com forte orientação para o aumento da produção por meio de insumos químicos e sintéticos e da intensa mecanização da produção, para o humanismo crítico, na qual a participação ativa do produtor é vista como fundamental. Assim, trabalhar métodos e técnicas com perspectiva crítica e participativa nada mais é que uma ação educadora (FREIRE, 1988). O mesmo autor descreve "se satisfazer com um mero adestrar, pode, inclusive, em certas circunstâncias, conseguir uma maior rentabilidade do trabalho. Entretanto, não terá contribuído em nada, ou em quase nada, para a afirmação deles como homens mesmo" (FREIRE, 1988, p. 43).

É necessário o diálogo e a comunicação do extensionista rural com o produtor, para que ambos busquem soluções para a produtividade e redução da desigualdade social, sem que o técnico imponha o seu saber como incontestável. É no diálogo que se torna possível uma relação de transformação da realidade, na medida em que o receptor não é mais visto como objeto e "depósito" de conhecimento, mas, se torna sujeito de transformação prática por meio da análise crítica das relações homem-homem e homem-natureza, superando a cultura do "medo" de perder seu trabalho e sua produção, que refletem na utilização de um "pacote tecnológico" oferecido pelos extensionistas.

Para tanto, o estudo da percepção dos estudantes sobre a extensão em seus diferentes tempos é fundamental para que eles percebam como ocorreu o processo de construção, ou seja, analisar sua compreensão como era realizada no passado, como é hoje, e como eles pretendem ou idealizam que será ou deve ser no futuro construindo uma reflexão crítica e emancipadora com os estudantes. De acordo com Tuan (1980, p. 4), é essencial observar o valor da percepção,

\begin{abstract}
A percepção é tanto a resposta aos estímulos externos, como a atividade proposital, na qual certos fenômenos são claramente registrados enquanto outros retrocedem para a sombra ou são bloqueados. Muito que recebemos tem valor para nós, para a sobrevivência biológica e para propiciar algumas satisfações que estão enraizadas na cultura.
\end{abstract}

Para Colchester (2002, apud Acserald, 2013, p. 19), os mapas participativos "revelaram-se ferramentas úteis para mobilizar a comunidade e gerar debates locais sobre demanda de terras, e, também, para planificar o manejo dos recursos naturais".

\section{Metodologia}

A pesquisa realizada caracterizou-se, quanto à natureza como aplicada e quanto aos objetivos como exploratória e descritiva. O caráter exploratório se dá pela necessidade de investigação da realidade para obter os dados necessários à elaboração de uma proposta de ação (GIL, 1999). 
O tema proposto para a execução deste trabalho foi uma reflexão sobre o papel da extensão e como ela vem sendo praticada no Brasil.

Para a execução dessa proposta foi escolhida a metodologia mapeamento participativo, em que se propôs realizar uma reflexão sobre o passado, presente e futuro da extensão, com o intuito de levantar dados e informações que por meio de reflexões e análises, possam gerar um panorama fidedigno da percepção dos estudantes de graduação em ciências agrárias e sociais. Assim, participaram aproximadamente 30 estudantes de graduação pertencentes a diferentes cursos - Direito, Educação Física, Engenharia Ambiental e Sanitária, Agronomia, Engenharia Florestal e Zootecnia, Química, Letras, Administração.

Dos vários instrumentos possíveis de serem utilizados, considerando o público alvo a ser pesquisado, o objetivo a ser atingido e a experiência dos pesquisadores com metodologias participativas em comunidades rurais, optou-se pela adoção de tal metodologia. Por meio de desenhos, a expressão torna-se mais lúdica e permite a interação dos integrantes conforme há um diálogo para construção do mesmo. E cada um tem possibilidade de se expressar.

As discussões promovidas entre o grupo de pós-graduação evidenciaram que para a aplicação da metodologia do mapeamento participativo, seria necessário um estímulo inicial nos discentes de graduação para que se desse um início a reflexão sobre o tema extensão. Diante disso, foi estabelecido que esse estímulo fosse iniciado por meio de música, como também por cartazes com frases que incitassem a reflexão.

Além disso, o grupo também considerou importante a entrega de um questionário para ter um retorno dos discentes frente à atividade e em relação a contribuição da experiência na sua formação.

A abordagem do tema proposto foi inspirada nos princípios teóricos de Coelho (2005), Callou et al. (2008) e também nas referências teóricas apreendidas de Freire (1993) associadas à reflexão sobre o papel da extensão rural nos dias atuais, com contribuição de outros autores em assuntos específicos.

Para execução da metodologia foi combinado dia e horário com a professora responsável da disciplina. A escolha do grupo se deu a partir do tempo condizente ao horário da aula, a fim de que fosse possível acontecer em tempo hábil à proposta metodológica e respeitando o calendário da disciplina.

Durante esse período foram promovidos encontros e discussão entre os integrantes do grupo desse trabalho (discentes de pós-graduação) para definir a condução da aplicação do mapeamento participativo visando promover uma reflexão sobre a Extensão e como ela vem sendo praticada no Brasil junto a uma turma de discentes de graduação da UFLA matriculados na disciplina eletiva de Fundamentos de Extensão. Esta tem como objetivo explorar o histórico da extensão rural, a extensão contemporânea e metodologias para abordá-la.

O primeiro contato do grupo com os discentes de graduação se deu em uma aula da disciplina de Fundamentos de Extensão, em que os integrantes desse grupo de trabalho acompanharam a aula a fim de conhecer e traçar um diagnóstico inicial dos estudantes da atividade proposta.

Assim, foram levantadas informações que, associadas a estudos bibliográficos deram subsídio para as reflexões aqui postas. Posteriormente, os dados coletados foram analisados à luz das teorias estudadas. Na sequência, o grupo do mestrado fez uma breve apresentação sobre o passado, o presente e o futuro da extensão rural no Brasil, no tempo estimado de 30 minutos. Após essa explanação, os estudantes da graduação fizeram uma análise e comparação do que foi dito pelo grupo de mestrandos e o que foi feito por eles.

Foi reservado 10 minutos para responderem por escrito as seguintes questões para conhecer um pouco do perfil dos estudantes, bem como, entender a contribuição da metodologia para com o aprendizado dos estudantes: idade; sexo: M ( ) F ( ); cidade de origem; Esta experiência contribuiu de alguma maneira para a sua formação relação a Extensão? Sim ( ) Não ( ). De que forma você, a partir dessa abordagem, poderá atuar contribuindo para sua própria formação? Em que mudou sua perspectiva sobre Extensão?

\section{Descrição Geral e Análise Os tempos da extensão e suas interpretações}

Em um primeiro momento, foram apresentados os estudantes do mestrado, equipe formada por cinco membros, e então foi explicado aos estudantes da graduação qual metodologia seria utilizada, bem como os objetivos do trabalho. Foram recebidos com a música "Tô" do autor Tom Zé, para que ao 
adentrarem no local se sentissem mais à vontade e de alguma maneira preparados para um momento de reflexão. Também foram dispostos naquele ambiente, cartazes contendo imagens e perguntas sobre a extensão com o objetivo de despertar neles sensações e uma reflexão inicial, que ao final foram discutidas.

Além da música para promover um início de reflexão, foram colados cartazes no quadro com problematizações como: O que é extensão? Como fazer extensão? Por que fazer extensão? Quem são os sujeitos da extensão? Onde fazer Extensão? E qual o conhecimento deve subvalorizado no processo de extensão (Figura 1).

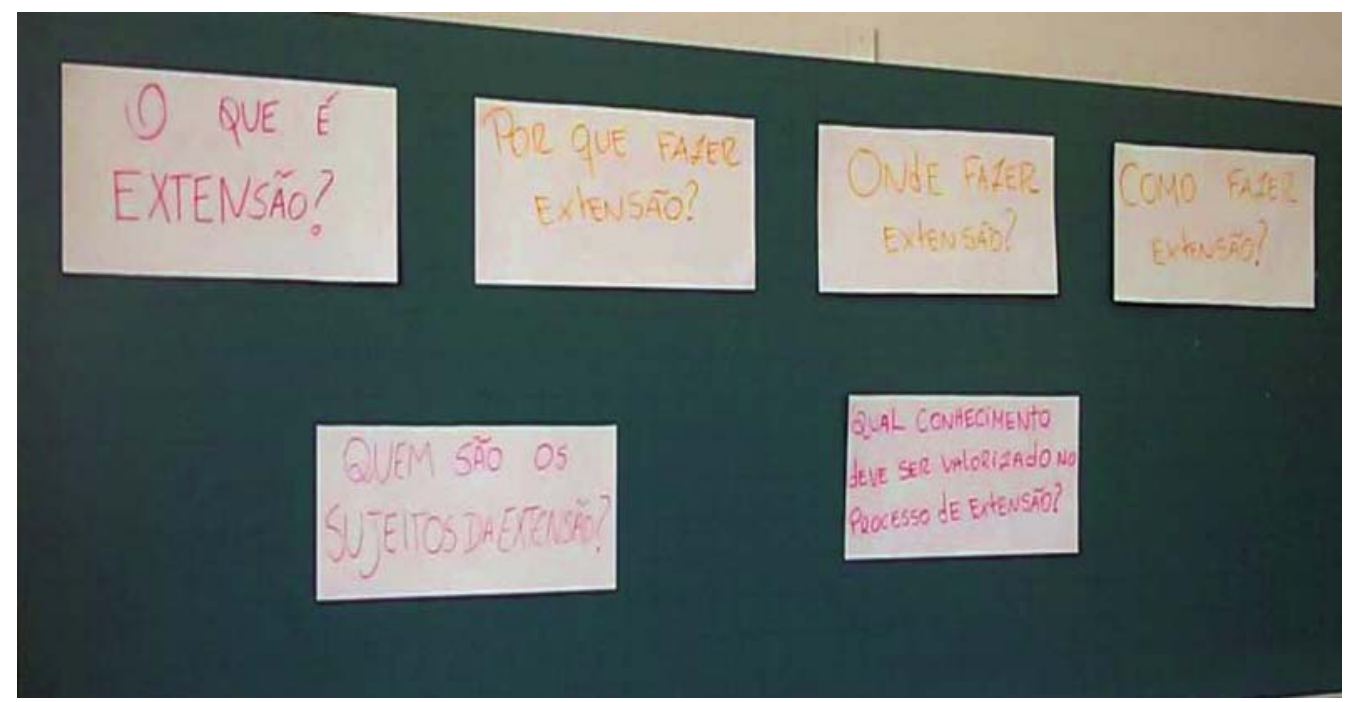

Figura 1 - Frases em cartazes dispostas no quadro para problematizar a extensão com os estudantes da disciplina de Fundamentos da Extensão.

Fonte: Dos autores, 2017.

Assim, foi proposta a construção dos mapas, pelos estudantes, em forma de desenhos que representassem a extensão rural no passado, presente e futuro. Nesse momento foram distribuídos cartolinas e giz de cera para colorir e desenhar, para todos os grupos. Para tal, o número de estudantes foi dividido por três, formando assim três grupos, que representaram por meio de desenhos o passado, o presente e o futuro da extensão rural no Brasil. Os estudantes tiveram 20 minutos para realizar essa atividade. Após a construção dos mapas cada grupo fez uma apresentação rápida explicando o porquê daquele desenho, momento em que cada fase da extensão rural foi discutida com o grupo, como forma de legitimar os dados obtidos e/ou acrescentar ou retirar alguma informação.

Apesar do uso de recursos para estimular a reflexão sobre o tema e extensão, a primeira impressão causada nos integrantes do grupo aplicador, foi que conforme os discentes iam entrando na sala, muitos nem sequer prestavam atenção nos cartazes expostos ou se mostravam interessados na música que estava tocando, permanecendo até o início propriamente dito da atividade, atentos em seus respectivos aparelhos celulares.

Assim, houve a apresentação da equipe e logo em seguida foi explicada a metodologia do mapeamento participativo e a atividade que eles deveriam executar: a construção de um desenho com o tema extensão, sendo que eles seriam divididos em grupos e que cada um retrataria por meio de desenhos a extensão num tempo, sendo estes: passado, presente e futuro. A reação dos discentes após a apresentação da atividade transpareceu num primeiro momento certo desinteresse "nossa, isso parece que vai ser bem chato".

Dando continuidade à atividade, os estudantes foram divididos em grupos: A (passado), B (presente) e C (futuro) e cada um deles se juntaram ao grupo que pertenciam. Após essa etapa foram distribuídos os materiais, cartolina, giz de cera e pincel para que dessem início a construção dos desenhos. No total 27 estudantes participaram da metodologia de mapeamento participativo.

O primeiro grupo começou a escrever ao invés de desenhar, e os mediadores orientaram que era para fazer um desenho do que representava o passado da extensão para eles, então, trocou-se de cartazes e os participantes começaram a esboçar. Apesar de apenas dois integrantes se disporem a desenhar, todos os integrantes participaram da construção do desenho. 
No segundo grupo que tratava do presente, apenas duas pessoas construíram o desenho. E foi preciso intervir para estimular a participação dos outros integrantes na construção do mesmo.

O grupo que ficou responsável por retratar o futuro da extensão se envolveu muito mais nas discussões antes de começar a desenhar em relação aos outros grupos. Quatro dos integrantes deste grupo dispuseram a sentar-se no chão para realizar o desenho e retratar em conjunto com os demais, o futuro da extensão.

Após o término da construção dos desenhos, dois integrantes de cada grupo se dirigiram ao quadro, expondo o desenho executado e explicaram-no.

O grupo que retratou o passado da extensão explicou o desenho realizado (Figura 2) de acordo como descrito:

\begin{abstract}
Antigamente que a "galera" tinha muito preconceito com o maquinário, queria dar uma revolução maior, eram muito conservadores. Então tentamos retratar as duas partes, uma fazendo corte manualmente, tendo mais trabalho, menos tempo para o consumo. E com o maquinário, fertilizante, adubo que veio depois a extensão, depois que implantou a extensão no Brasil a gente conseguiu ter uma evolução maior, principalmente em tecnologia, ganho de tempo, na parte de evolução.
\end{abstract}

O outro integrante explicou que também "mostra o agricultor que está lá se perguntando se isso aqui é o melhor jeito, se isso ia produzir, se ia dar certo."

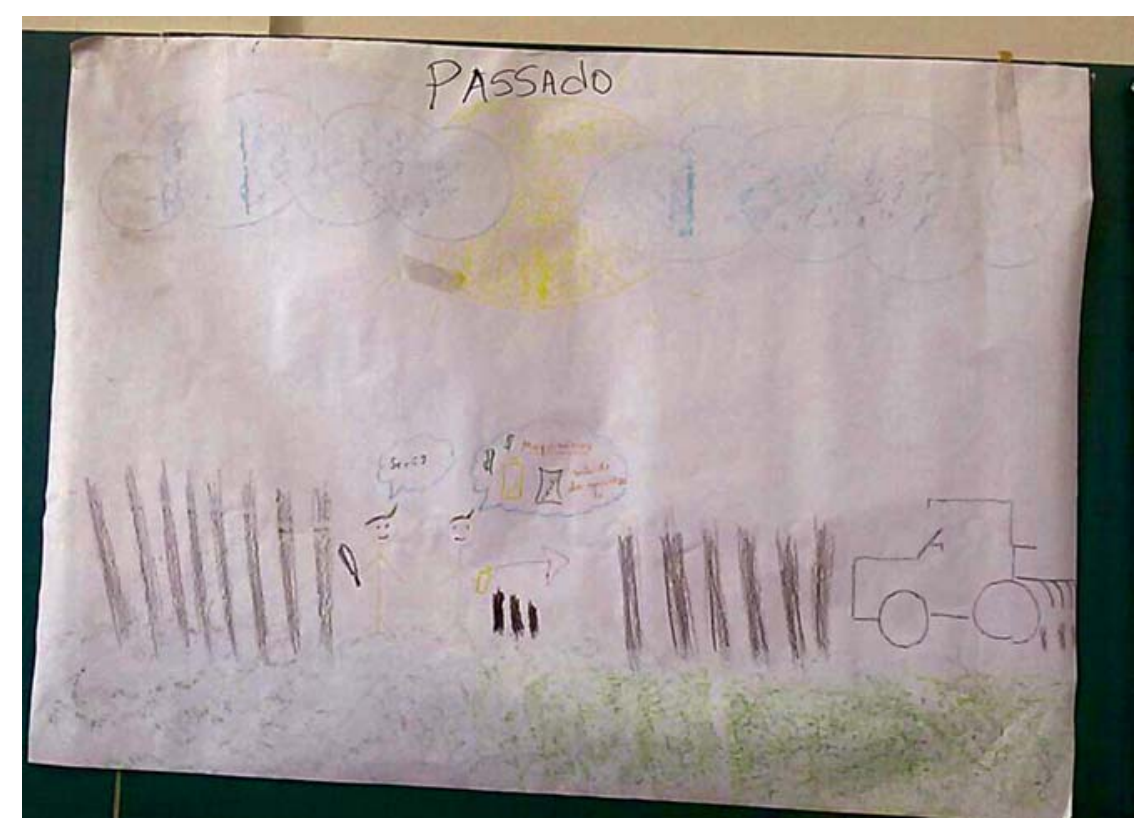

Figura 2 - Foto descrevendo o passado de acordo com o grupo A.

Fonte: Dos autores, 2017.

Após a explicação dos participantes, houve a intervenção de um integrante do grupo A relatou:

Que eles não procuravam ver o outro lado, não procuravam aprofundar em pesquisa. Em relação à extensão no Brasil quiseram trazer a tecnologia e modernização da agricultura, foi ai que começou a se pensar se realmente se o que fazia era a forma mais correta, forma mais fácil, mais prática, com a tecnologia melhor, então foi utilização do tempo, modernização, que só começou com a extensão e suas fases.

Nesse período, o integrante mediador intervém e discorre que o momento é de ideologia de modernização pautada em um modelo de difusão de tecnologia. Já o papel do extensionista era de 
especialista responsável pela difusão de pacotes tecnológicos, por exemplo: pro-várzeas (irrigação), polo centro (expansão das fronteiras agrícolas). Como? Informava e persuadia os agricultores para adquirirem insumos, sementes, máquinas, propagandas massivas do governo falando em desenvolvimento, mas mostrava grandes destruições, como exemplo, derrubada de árvores. A forma de comunicação era emissor - mensagem- receptor (apenas uma via), a inovação chegava invadindo o espaço histórico cultural sem a criação de métodos e práticas adequadas à realidade dos agricultores. Como efeitos negativos destacam-se a subordinação da agricultura à indústria, a desvalorização do conhecimento dos agricultores, a salinização de alguns solos pelo uso de fertilizantes e agrotóxicos, a contaminação dos recursos hídricos, a erosão e o assoreamento de mananciais.

Para tanto, descreve que o termo extensão rural não é autoexplicativo. Desde a implantação do modelo cooperativo de extensão americano foram muitas as iniciativas de conceituação de extensão rural. Os conceitos evoluíram com o tempo e com as mudanças conjunturais, estrutura socioeconômica e cultural de cada país. As indústrias produtoras de insumos e equipamentos, as revendas agropecuárias e as agroindústrias (processadoras de matéria prima agropecuária), em geral, prestam serviços caracterizados como assistência técnica. descrito:

O grupo que retratou o presente da extensão explicou o desenho realizado (Figura 3) conforme

Quisemos expor os dois meios, tanto o rural e o urbano e que basicamente quis dizer com o desenho que a extensão hoje existe, mas ainda há um caminho muito grande para percorrer para que ela chegue a todos os caminhos, tanto no meio rural quanto no meio urbano.

Os integrantes do grupo ainda ressaltaram que: a extensão rural tem grande importância para todo mundo, tanto para o meio rural quanto o urbano. Colocaram ainda que: os meios, tanto rural quando o urbano não dialoga e que essa falta de comunicação não permite uma maior eficiência da extensão impossibilitando seu sucesso.

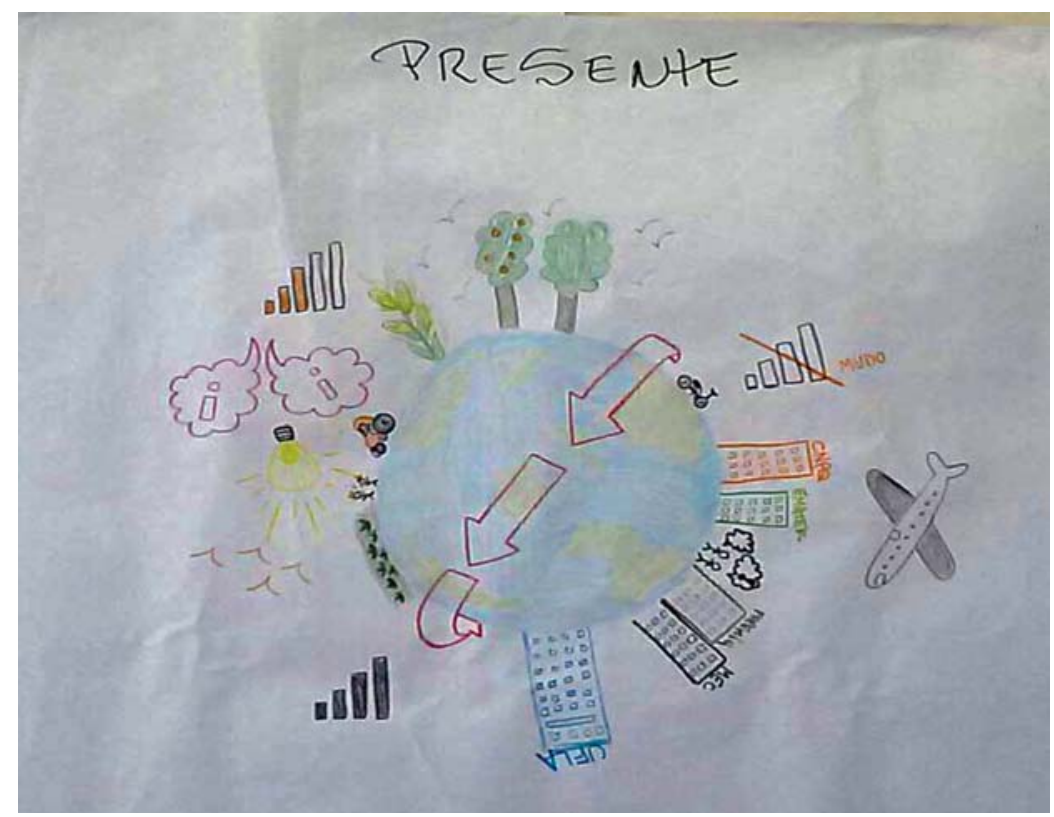

Figura 3 - Foto de demonstração do presente de acordo com o grupo B.

Fonte: Dos autores, 2017.

A mediadora interviu, após a apresentação do grupo sobre o presente da extensão e explicou que esse tempo é a extensão transcendendo o meio rural, evidenciando a necessidade da extensão em todos os meios tanto no rural quanto no urbano. Ela também descreveu que a extensão no passado era colocada de uma forma praticamente imposta, sem considerar os interesses do outro, pautada apenas no interesse econômico, e perguntou para a turma se a extensão continua assim ou se houve alguma mudança. Os integrantes do grupo B apontaram que atualmente há mais base dos conceitos e da 
melhor forma de se fazer, mas ainda há muito para se construir. Um dos integrantes ainda ressalta que: mesmo estando dentro da UFLA não tinha muita noção sobre extensão e com a disciplina ele tem percebido que há ainda muita informação para ser construída.

Foi ressaltado que a partir dos anos 1980 houve mudanças nas questões políticas e uma nova extensão começou a surgir, considerando o pensamento de Paulo Freire no qual a comunicação se torna fundamental para poder ouvir, conhecer e valorizar os anseios do outro. Essa é a extensão que acontece hoje, uma extensão que busca ouvir e não só impor o que deve ser feito.

A mediadora coloca também que a extensão do passado priorizava os médios e grandes produtores com o uso excessivo de agroquímicos e compra de equipamentos. Em contrapartida nos dias atuais há uma forte corrente voltada para a agricultura familiar, que se preocupa não só com os bens produzidos, mas com a qualidade de vida das pessoas. No entanto, a mediadora discorre que, ainda é necessário evoluir para alcançar uma extensão "perfeita" uma vez que prevalecem muitos elementos da extensão do passado. Ressalta que já existem muitas metodologias participativas, inclusive a que foi utilizada a do mapeamento participativo - mas ainda há muito trabalho para concretizar a extensão dialógica e participativa.

Outro mediador ressalta, dentro do presente da extensão que no final da década de 1970 e 1980 , grandes empresas investiram em um discurso no qual era necessário o produtor rural aumentar seus lucros, plantando grandes porções de terra com apenas uma espécie cultivada, controlando pragas e insetos com uso de pesticidas e fertilizantes de maneira a garantir a produção de alimentos para uma população cada vez maior no mundo. Assim, de acordo com Fritjof Capra (2002, p. 184):

\begin{abstract}
A verdade nua e crua é que a maioria das inovações na área de biotecnologia alimentar foi motivada pelo lucro e não pela necessidade. A Monsanto, por exemplo, projetou uma soja transgênica que resiste especificamente ao herbicida Roundup, da mesma empresa, para aumentar as vendas deste último produto. Produziu, além disso, sementes de algodão portadoras de um gene inseticida a fim de aumentar as vendas de sementes. Tecnologias como estas aumentam a dependência dos agricultores em relação a produtos patenteados e protegidos por "direitos de propriedade intelectual", que lançam na ilegalidade as antiquíssimas práticas agrícolas de reproduzir, armazenar e trocar sementes.
\end{abstract}

Portanto, a chamada revolução verde expulsou agricultores do campo que foram marginalizados nas cidades, um desastre para a saúde do solo, humana e para as relações sociais. Pode ser destacado como um desafio ao profissional de extensão no Brasil a questão da formação e posterior abordagem junto ao produtor rural, de uma maneira holística e interdisciplinar. Considerando que o agricultor familiar não possui conhecimento formal, mas sim grande conhecimento dos processos produtivos por meio da vivência e experiência, é um desafio a este profissional extensionista conseguir ouvir e aprender com esses produtores. Afinal, a universidade tem ações ainda distantes da sociedade, é preciso se envolver mais as questões sociais. Sobre essa dificuldade Saviani (1981) discorre:

A função da extensão deveria significar a articulação da universidade com a sociedade, de tal modo que aquilo que ela produz em termos de novos conhecimentos e aquilo que ela difunde através do ensino não ficassem restrito apenas aqueles elementos que conseguem ser aprovados no vestibular e que integram determinado curso objetivando se forma numa determinada profissão. Ao contrário, cabe à universidade socializar seus conhecimentos, difundindo-os à comunidade e convertendo, assim, numa força viva capaz de levar o nível cultural geral da sociedade (SAVIANI, 1981, p. 73).

Ademais, compreende-se que a extensão promove a interação e a troca de saberes entre a comunidade universitária e a sociedade, sendo um instrumento indispensável à plena realização da universidade como instrumento emancipatório. Ela funciona como processo educativo emancipador, construtivista, democrático que se realiza mediante técnicas e metodologias participativas, capazes de contribuir para o fortalecimento da cidadania e a construção de estilos de desenvolvimento rural sustentável.

E dessa maneira construir junto com agricultor, ferramentas e processos de desenvolvimento, tentando encontrar soluções aos problemas cotidianos como a gestão da propriedade, o associativismo 
e o cooperativismo, visto que, ainda prevalece uma estrutura machista e patriarcal replicada por toda nossa sociedade.

Dessa forma, observa-se que o conhecimento é tarefa a ser construída em conjunto, entre sujeitos. Para tanto, em diálogo com o pensamento freiriano, deseja-se enfatizar aos discentes que "o conhecimento não se estende do que se julga sabedor até aqueles que se julga não saberem; o conhecimento se constitui nas relações homem-mundo, relações de transformação, e se aperfeiçoa na problematização crítica destas relações" (FREIRE, 2006, p. 36).

O grupo C que apresentou sobre o futuro da extensão (Figura 4) descreveu o desenho da seguinte forma

Seria uma extensão que frisasse o meio urbano e rural, a universidade, órgãos de extensão e o meio ambiente de forma que tudo isso estejam interligados.

Outro integrante interviu contribuindo:

Representamos com o círculo que está tudo interligado, não só no meio urbano, mas a sociedade como num todo, em que questão da informação, não só na questão da extensão agrícola, mas nas escolas de terem mais espaços nas universidades, integrando tudo. E em questão do meio rural tendo mais informação com novas tecnologias, mas que seja adaptado, às vezes o produtor não vai querer implantar certa tecnologia porque ele não tem conhecimento, ou porque usa determinada tecnologia há anos e funciona, então para que trocar? No futuro a gente acredita que essas pessoas que tem certo tipo de realidade vão mudando, justamente pela informação, ter maior acesso a informação.

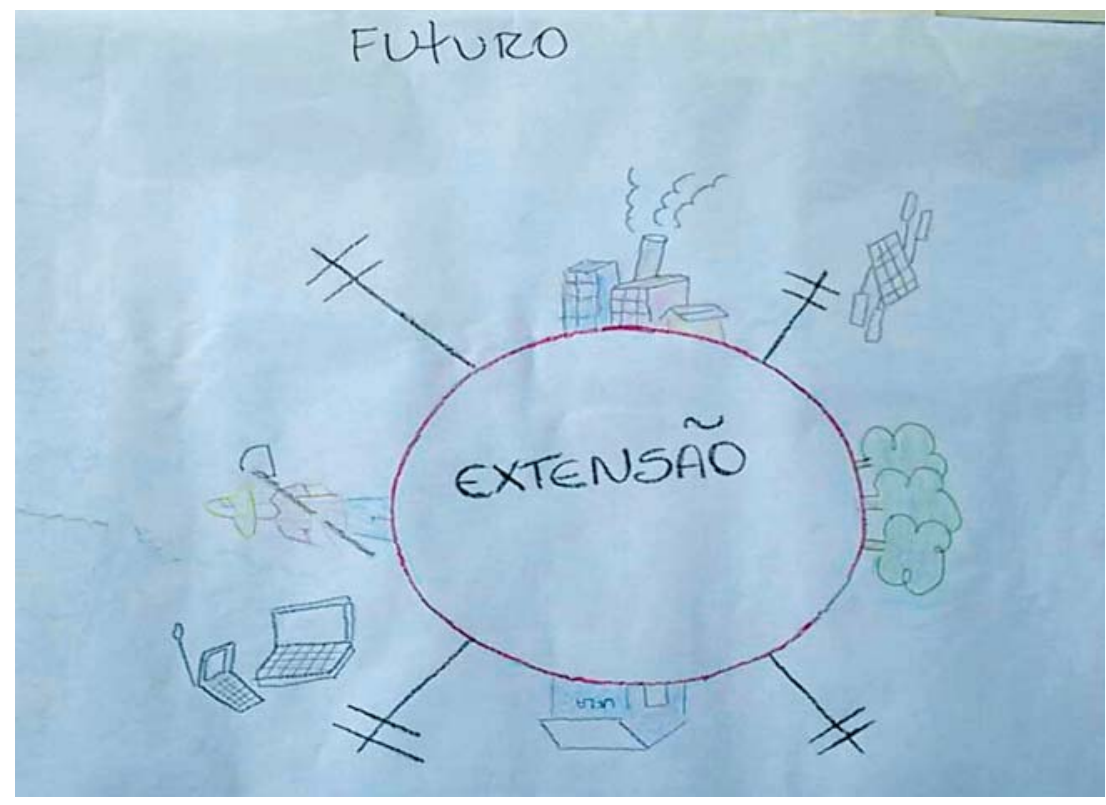

Figura 4 - Foto de demonstração do presente de acordo com o grupo C.

Fonte: Dos autores, 2017.

Após a fala do estudante sobre o futuro da extensão, o mediador problematizou "quem somos nós para indicar o futuro da Extensão no Brasil?". Todos são sujeitos da Extensão, educadores-educandos e ao mesmo tempo educandos-educadores, em que é preciso aproximar da sociedade o ensino e pesquisa gerados na Universidade, por meio do diálogo. Mas, primeiramente é necessário formar mais e melhores os extensionistas, que tenham em sua atuação profissional o compromisso com o diálogo para análise crítica da realidade, e assim construir uma sociedade mais justa e menos desigual.

Conforme Paulo Freire, "se a pura tomada de consciência das coisas não constitui ainda um 'saber cabal', já que pertence à esfera da mera opinião, como enfrentar a superação desta esfera por 
aquela em que as coisas são desveladas e se atinge a razão das mesmas?" (FREIRE, p. 1988, p. 26). A resposta necessariamente passa pelo diálogo e abordagem por parte do técnico, tratando o sujeito que necessita de alguma ajuda como sujeito, e não como objeto.

A extensão sofreu transformações com o passar dos anos. Em sua primeira fase, de 1948 a 1962 tinha um enfoque Humanismo assistencialista e na segunda fase, nos anos 1963 a 1984, o difusionismo produtivista era embasador das ações. Nessas duas primeiras fases, uma visão conservadora mantinha vigência e na sua $3^{\circ}$ terceira fase, de 1985 - 1989, sob um olhar de Humanismo Crítico (RODRIGUES, 1997). Sob uma perspectiva de Nova Extensão Rural (CAPORAL, 1998). Para tanto, cabe ao futuro, como estudantes, professores, técnicos construir uma extensão no sentido de emancipar por meio do diálogo, da coletividade.

Assim, o trabalho desenvolvido com os estudantes da graduação, possibilitou alguns questionamentos quanto ao papel da extensão em relação à comunidade acadêmica ao longo dos próximos anos, e tentou, dessa maneira, despertar a reflexão da realidade vivenciada, na qual desejasse construir, não só para a extensão rural, mas uma reflexão da Extensão em si. Por exemplo, questionou-se qual deve ser o papel dos estudantes de Direito da UFLA, junto à comunidade de Lavras, durante as eleições presidenciais de 2018 e quais atividades de extensão poderiam ser desenvolvidas pelos estudantes da primeira turma do curso de Medicina da Universidade, quando atingirem o último ano da graduação.

E ainda, como deveria ser a abordagem de um agricultor familiar orgânico, por um Engenheiro Agrônomo recém-formado na UFLA, contratado por uma revenda de defensivos agrícolas da região? Notou-se que essas questões fizeram a maioria dos estudantes refletirem por um momento, e houve participação por meio de ideias e compartilhamento de opiniões. Aqueles que participaram, disseram que realmente podem contribuir para a discussão da importância das eleições presidenciais que se aproximam, assim como o esclarecimento da confusão de partidos, fidelidade partidária, reforma política e trabalhista do nosso país, que são questões que atingem diretamente o cotidiano do cidadão.

É necessário pensar formas de atuação dos estudantes, que contribuam efetivamente com a sociedade por meio da Extensão, de maneira que essa atuação seja prazerosa de se fazer e atrativa, tanto para os universitários brasileiros, quanto para a sociedade que necessita de maior esclarecimento e acesso ao conhecimento gerado no Brasil.

Quando questionados se a experiência contribuiu de alguma maneira para a sua formação em relação à Extensão, todos responderam que sim.

Em relação ao questionamento "de que forma, a partir dessa abordagem, poderá contribuir para a sua formação?", dentre alguns relatos:

A partir dessa abordagem fica mais evidente não só a necessidade de praticar extensão, mas também o dever tanto com a sociedade quanto com nós mesmos, afinal a extensão é uma via de mão dupla em que o conhecimento é transmitido para ambas às partes.

Entendo que praticar extensão é de certa forma, estender o conhecimento que adquirimos na graduação para comunidade de forma participativa, promovendo a troca de experiências entre os envolvidos. Acredito que a abordagem nos fez refletir sobre a importância da extensão e sobre as formas que podemos praticá-la.

Por meio de participações democráticas e possíveis envolvimentos com a comunidade. Buscar sempre o diálogo, que traz certo conhecimento. Essa abordagem nos conscientiza e nos alerta em vários pontos.

Outro questionamento: "em que mudou sua perspectiva sobre Extensão?", o mesmo participante respondeu,

Todos aqueles que possuem um conhecimento técnico são agentes de possíveis transformações através da extensão, porém todo conhecimento deve ser valorizado.

Que precisamos ter uma percepção sobre nosso contexto atual para praticá-la. Trouxe mais clareza sobre o assunto, destacando a importância de um maior envolvimento com os diversos setores da comunidade. Mudou no sentido de entender o que é Extensão, que é muito mais uma troca de conhecimento e experiência. Através do diálogo, do que impor o que achamos melhor ao receptor da extensão. 
Para finalizar e refletir solicitou aos grupos $\mathrm{A}, \mathrm{B}$ e $\mathrm{C}$ que respondessem as questões que foram dispostas no quadro "O que é extensão? Como fazer extensão? Por que fazer extensão? Quem são os sujeitos da extensão? Onde fazer Extensão? E qual o conhecimento deve subvalorizado no processo de extensão" a fim propiciar uma reflexão conjunta das perguntas realizadas e das respostas colhidas (Figura 5).

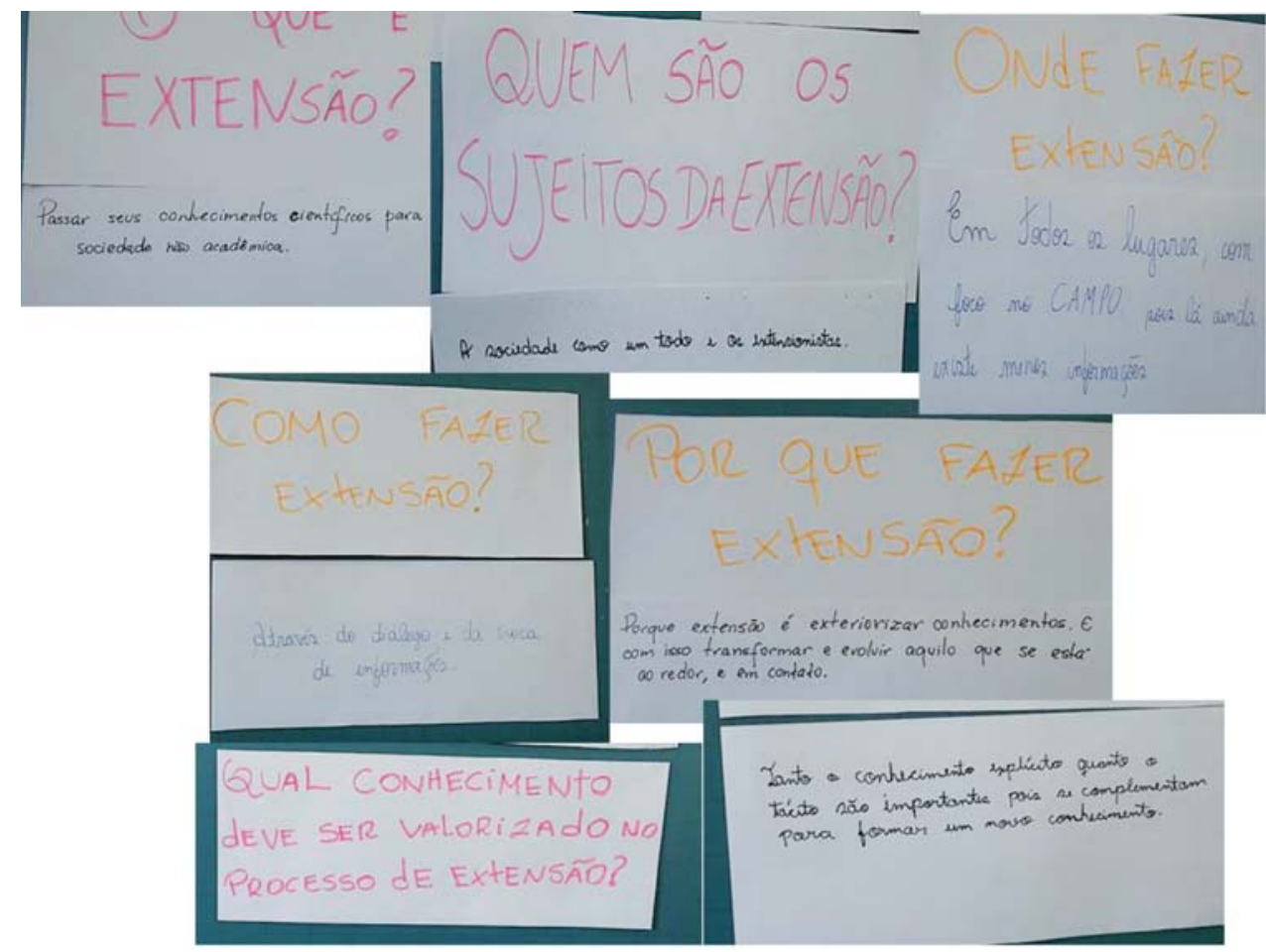

Figura 5 - Questões e suas respectivas respostas descritas pelos grupos A, B e C.

Fonte: Dos autores, 2017.

A resposta do grupo para "o que é 'extensão'?"; foi: "Passar os seus conhecimentos científicos para a sociedade." O mediador perguntou se todos concordavam com a resposta em relação ao que é extensão, e um dos integrantes acrescentou que extensão é "construir o conhecimento, não só passar, mas também adquirir". O grupo que conduzia a dinâmica achou essa resposta excelente, demonstrando que o aluno havia refletido e apreendido a essência da extensão, que foi o propósito.

O papel do extensionista é contribuir para a solução dos problemas do cliente. Trata-se de uma relação entre o conselheiro e o agricultor, uma relação entre dois atores (díade). Os papéis devem ser apreensíveis e as tarefas descritíveis, não podendo ser assumidos compromissos para os quais os extensionistas não possuem a qualificação nem o tempo.

O mediador continuou compartilhando que esse diálogo é um exercício que precisa ser feito diariamente, assim como a reflexão de não depositar o conhecimento em uma conta bancária, mas de construir juntos o conhecimento e refletir o diálogo. A resposta para a pergunta "quem são os sujeitos da extensão?" foi, "a sociedade como um todo e os extensionistas". Então, o mediador sugeriu a leitura do autor Paulo Freire, no qual existe bastante referência ao termo "sujeito da extensão", e se opõe ao conceito de objeto em que é depositado o conhecimento. Reforçou-se que a lógica é que todos nós somos o sujeito da extensão.

Em seguida foram focalizadas as questões do "por que fazer?" e "onde fazer extensão?". E as respostas foram respectivamente: "Porque extensão é exteriorizar conhecimentos, e com isso transformar e evoluir aquilo que se está ao redor e em contato". Então o mediador salientou na resposta a palavra transformar, em que o porquê fazer extensão é conseguir realmente causar transformações na sociedade. Se uma situação está assim hoje e pode ser diferente, uma vez que ela não está sendo benéfica para sociedade, então é por meio dessa construção de conhecimento de forma conjunta na sociedade que se torna possível à transformação. 
Continuou apontando onde é feita a extensão, confirmando que realmente no campo observa-se existir menos informação de cunho científico, devido ao distanciamento das instituições de ensino e pesquisa com a sociedade. A extensão deve ser realizada em todos os lugares, pois todos os campos de conhecimento têm abertura para extensão. Todas as áreas de conhecimento têm motivos para fazer extensão. No campo do Direito, por exemplo, os estudantes podem orientar as mulheres que residem nas comunidades sobre a Lei Maria da Penha, pois há casos de maridos agredirem suas esposas, além de outras ações que podem contribuir com a qualidade de vida da população.

Finalmente, foram abordadas as questões de "Como fazer extensão?" sendo a resposta "através do diálogo e da troca de informação". O grupo preferiu não acrescentar nem retirar nada. E, na última questão de análise, perguntou-se "qual conhecimento deve ser valorizado na extensão?", com uma abrangente resposta de "tanto o conhecimento explícito quanto o tácito, pois ambos são importantes e se complementam para formar um novo conhecimento". O mediador corroborou a afirmação e chamou atenção para a importância do conhecimento empírico das pessoas.

O extensionista, muitas vezes, se depara no campo com um sujeito que não possui o conhecimento formal gerado na academia, mas possui conhecimento "de causa" - prático - muito maior que o conhecimento - técnico - do extensionista. É necessário compreender que todo indivíduo tem um conhecimento a ser compartilhado, que deve ser levado em consideração. A dinâmica foi então encerrada com o mediador explicando que demonstramos a metodologia para que os estudantes tivessem a prática da extensão, de maneira a se chegar a algum conhecimento do tema. Nesse sentido, segundo Freire, a relação entre agrônomo e agricultor deve estar amparada na construção de uma relação dialógica. "A educação é comunicação, é diálogo, na medida em que não é transferência de saber [...]" (FREIRE, 1992, p. 69).

Buscou-se facilitar a discussão diante de um ramo do conhecimento ainda negligenciado na academia, de acordo com o levantamento bibliográfico. Dessa maneira, a intenção foi refletir sobre extensão a fim de que esses estudantes possam ser multiplicadores da extensão e contribuir na construção do diálogo. Para tanto, "a tarefa do educador, então, é de problematizar aos educandos o conteúdo que os mediatiza, e não a de dissertar sobre ele [...]. Neste ato de problematizar os educandos, ele se encontra igualmente problematizado" (FREIRE, 1992, p. 81). O diálogo problematizador diminui "a distância entre a expressão significativa do técnico e a percepção pelos camponeses em torno do significado". (FREIRE, 1992, p. 68). A problematização provoca um "retorno crítico à ação", consequentemente reflexão sobre o próprio ato, para agir melhor com os demais na realidade (FREIRE, 1992, p. 82-83).

Portanto, quando reservou um tempo para preparar toda essa dinâmica a fim de refletir sobre a extensão, alcançou-se também uma transformação interna dos pesquisadores, haja vista que, o aprendizado deve ser em conjunto. Desse modo, para uma extensão embasada no diálogo, “[...] educador e educando assumam o papel de sujeitos cognoscentes, mediatizados pelo objeto cognoscível que buscam conhecer" (FREIRE, 1992, p. 28). Por meio do diálogo, até mesmo o conhecimento científicotécnico é problematizado "em sua indiscutível reação com a realidade concreta, na qual se gera e sobre a qual incide, para melhor compreendê-la, explicá-la, transformá-la" (FREIRE, 1992, p. 52).

\section{Considerações Finais}

A intenção, com a apresentação do presente trabalho, foi demonstrar que o diálogo e a problematização com outros estudantes são o caminho para compreender as influências do passado sobre o presente, possibilitando a tomada de decisão sobre o futuro de maneira consciente. E assim, por meio dessa dinâmica, espera-se que os estudantes percebam a importância da construção conjunta de metodologias de extensão e como a formação de cada um pode influenciar nesse momento, de forma positiva ou não. É fundamental que exista uma sensibilização e abertura por parte de todos os participantes, objetivando ter um novo olhar perante o que é proposto pelo outro.

Assim sendo, a professora que disponibilizou o tempo e o espaço para aplicar a metodologia, complementou e enriqueceu a apresentação agradecendo pelo trabalho dinâmico. Uma vez que metodologia utilizada possibilita gerar uma série de interações e, como ela já havia chamado atenção da turma em outras oportunidades, a construção do conhecimento e do saber é facilitada quando são utilizadas diferentes formas de aprendizagem, diferentes formas de práticas, abordagens e formas de tentar aprender. 
Afinal, não refletiu que os indivíduos não são máquinas que recebem uma série de informações e processam as mesmas. Cada um dentro da sua especificidade tem diferentes aspectos, diferentes potenciais e, utilizando-se de diferentes metodologias, é possível favorecer o processo de aprendizagem, uma vez que esta não depende apenas de quem desenvolve e conduz o trabalho (diagnóstico participativo), mas depende também de quem está interessado em conhecer em refletir sobre o diálogo e a extensão.

É importante ressaltar que a extensão rural é fundamental no processo de comunicação de novas tecnologias, geradas pela pesquisa, e de conhecimentos diversos, essenciais não só ao desenvolvimento rural, mas no seu sentido mais amplo.

\section{Referências}

ACSELRAD, H. Disputas cartográficas e disputas territoriais. In: Cartografias sociais e território. Henri Acselrad (organizador). Rio de Janeiro: Universidade Federal do Rio de Janeiro, Instituto de Pesquisa e Planejamento Urbano e Regional. 2008. 168 p.

CALLOU, A. B F. et al. O estado da arte do ensino da extensão rural no Brasil. Revista Extensão Rural, v. 15, n. 16, p. 84-115, 2008.

CAPORAL, F. R. La extensión agraria del sector público ante los desafíos del desarrollo sostenible: el caso de Rio Grande do Sul, Brasil. Tese (Doutorado)-Programa de Doctorado en Agroecología, Campes. 1998. 517 p.

CAPRA, F. As conexões ocultas: ciência para uma vida sustentável. Tradução Marcelo Brandão Cipolla. São Paulo, SP. Cultrix. 2002. 296 p.

COELHO, F. M. G. A arte das orientações técnicas no campo: concepções e métodos. Viçosa, MG: Suprema. 2 ed. 2014. 139 p.

COLCHESTER, M. O mapeamento como ferramenta para garantir o controle comunitário: alguns ensinamentos do sudeste asiático. WRM, Boletim nº 63. 2002.

FREIRE, P. Extensão ou comunicação? Rio de Janeiro: Editora Paz e Terra. 10.ed.. 1992. 93p. (Primeira publicação 1974).

FREIRE, P. Pedagogia do Oprimido. Rio de Janeiro: Editora Paz e Terra. 21.ed. 1993. 184p. (Primeira publicação 1974).

GOMES, F. M. H. Mapas participativos: quando os povos grafam seu mundo - o caso do mapeamento biorregional nas comunidades quilombolas do Kaonge, Dendê, Kalembá, Engenho da Ponte e Engenho da Praia. 2015. 71 p.

MOTA, N. L. C et al. Da Extensão Rural difusionista aos Sistemas Agroflorestais: uma breve discussão1. Intercom. 2006. 11 p.

ROMANIELLO, M. M.; ASSIS, T. R. de P. Extensão rural e sustentabilidade: guia de estudos. Lavras, UFLA. 2015. 114 p.

RODRIGUES, C. M. Conceito de seletividade de políticas públicas e sua aplicação no contexto da política de extensão rural no Brasil. Cadernos de Ciência \& Tecnologia, Brasília, v. 14, n. 1, 1997. p. 113-154.

SAVIANI, D. Escola e Democracia. Edição Comemorativa. Campinas: Autores Associados. 2008. 112 p.

TUAN, Yi - Fu. Topofilia: um estudo da percepção, atitudes e valores do meio ambiente. Tradução de Lívia de Oliveira. Londrina, PR: Eduel. 2012.

VIONE, G. F. Metodologias participativas na construção de planos de desenvolvimento local. Instituto de Ciências Humanas e Sociais, Curso De Pós-Graduação em Desenvolvimento, Agricultura e Sociedade. UFRRJ. 2002. 47 p.

Recebido para publicação em 11/3/2018 e aprovado em 21/06/2018. 